\title{
Melanoma of the skin and laterality
}

\author{
Graça M. Dores, MD, MPH ${ }^{a, c},{ }^{\star}$, Mark M. Huycke, MD ${ }^{a}, b$, and Susan S. Devesa, PhD $^{C}$ \\ a Department of Veterans Affairs Medical Center, Oklahoma City, OK \\ b University of Oklahoma Health Sciences Center, Oklahoma City, OK \\ c Division of Cancer Epidemiology and Genetics, National Cancer Institute, Bethesda, MD
}

\begin{abstract}
We were intrigued by the study of Butler and Fosko reporting a left-sided predominance of skin cancers, particularly among men.1 However, findings for melanoma were inconclusive due to the limited number of cases available for analysis. Therefore, using the large numbers of cases available in the Surveillance, Epidemiology and End Results (SEER) Program, we assessed the incidence of melanoma diagnosed among White residents of 12 SEER registry areas during 1992-2006.2 Histology and topography information are classified according to the International Classification of Diseases for Oncology, third edition.3 Age-adjusted incidence rates (IRs) and IR ratios (IRRs) were estimated for all cutaneous (C-440-449) melanomas (M-8720-8790) for sites with more than $70 \%$ of cases having specified laterality: eyelid $(n=777 ; 99 \%)$, ear $(n=4,772 ; 99 \%)$, other face $(n=19,273 ; 91 \%)$, trunk $(\mathrm{n}=29,329 ; 71 \%)$, upper extremity $(32,237 ; 99 \%)$, and lower extremity $(23,679 ; 99 \%)$.
\end{abstract}

Among males, incidence of left-sided melanoma was significantly higher than right-sided melanoma across all skin sites, ranging from 7-26\% (Table 1). Among women, significantly higher IRs for left-sided melanoma were limited to the face, and upper and lower extremities, although left-sided lesions predominated at all sites (IRRs 1.03-1.15). A leftsided predominance was observed for in situ and invasive melanoma at all sites among males, in contrast to women who had nearly equal or a slight right-sided predominance for in situ melanoma of the ear and trunk and invasive melanoma of the eyelid. Except for eyelid melanoma among older women, left-sided melanoma predominated at all sites among younger ( $<60$ years) and older (60+ years) men and women. Age and histology laterality patterns, particularly among men, were generally similar for younger individuals and superficial spreading melanoma and for older individuals and lentigo maligna melanoma. A significantly higher incidence of right-sided than left-sided melanoma was not observed at any site by gender, behavior, age, or histology.

As discussed by Butler and Fosko, ${ }^{1}$ a predilection for left-sided skin cancers in the United States is postulated to be related to ultraviolet light (UV) exposure while driving. Findings from our study support this hypothesis, despite the imperfect correlation between site of melanoma occurrence and UV intensity at exposed sites. ${ }^{4}$ With few exceptions, a greater left-to-right predominance was observed among men than women, suggesting that women

\footnotetext{
*Correspondence to: Graça M. Dores, MD, MPH, Department of Veterans Affairs Medical Center, 921 N.E. $13^{\text {th }}$ Street, Oklahoma City, OK, 73104, doresg@mail.nih.gov, Fax: 405-456-1569.

Conflicts of interest: The authors have no conflict of interest to declare.

Prior presentation: This work has not been previously presented.

Publisher's Disclaimer: This is a PDF file of an unedited manuscript that has been accepted for publication. As a service to our customers we are providing this early version of the manuscript. The manuscript will undergo copyediting, typesetting, and review of the resulting proof before it is published in its final citable form. Please note that during the production process errors may be discovered which could affect the content, and all legal disclaimers that apply to the journal pertain.
} 
may experience more equally distributed sun exposure, including possibly spending more time in the passenger seat. In addition, use of and types of UV-protective attire and accessories, use of sunscreen and sites of application, duration and intensity of UV exposure, and varying outdoor activities likely contribute to the gender-, age-, and histologyrelated laterality patterns we observed. Future studies that incorporate information on these factors may help to elucidate reasons for the laterality differences noted in our study and that of Butler and Fosko.1 However, in combination, these findings suggest that increased awareness and protection from situations associated with asymmetric UV exposure may help decrease the incidence of UV-related skin cancers.

\section{Acknowledgments}

Funding sources: Department of Veterans Affairs Medical Center, Oklahoma City, OK and Division of Cancer Epidemiology and Genetics, National Cancer Institute, Bethesda, MD.

\section{References}

1. Butler ST, Fosko SW. Increased prevalence of left-sided skin cancers. J Am Acad Dermatol.

2. Surveillance, Epidemiology and End Results (SEER) Program. National Cancer Institute, DCCPS, Surveillance Research Program, Cancer Statistics Branch; SEER*Stat Database: Incidence SEER-13 Regs Public-Use, Nov 2008 Sub (1992-2006). (www.seer.cancer.gov)released April 2009, based on the November 2008 submission

3. Fritz, A.; Percy, C.; Jack, A.; Shanmugaratnam, K.; Sobin, L.; Parkin, DM., et al., editors. International Classification of Diseases for Oncology. 3. Geneva (Switzerland): World Health Organization; 2000.

4. Gruber, SB.; Armstrong, BK. Cutaneous and ocular melanoma. In: Schottenfeld, D.; Fraumeni, JF., Jr, editors. Cancer Epidemiology and Prevention. New York: Oxford University Press; 2006. p. 1196-229. 


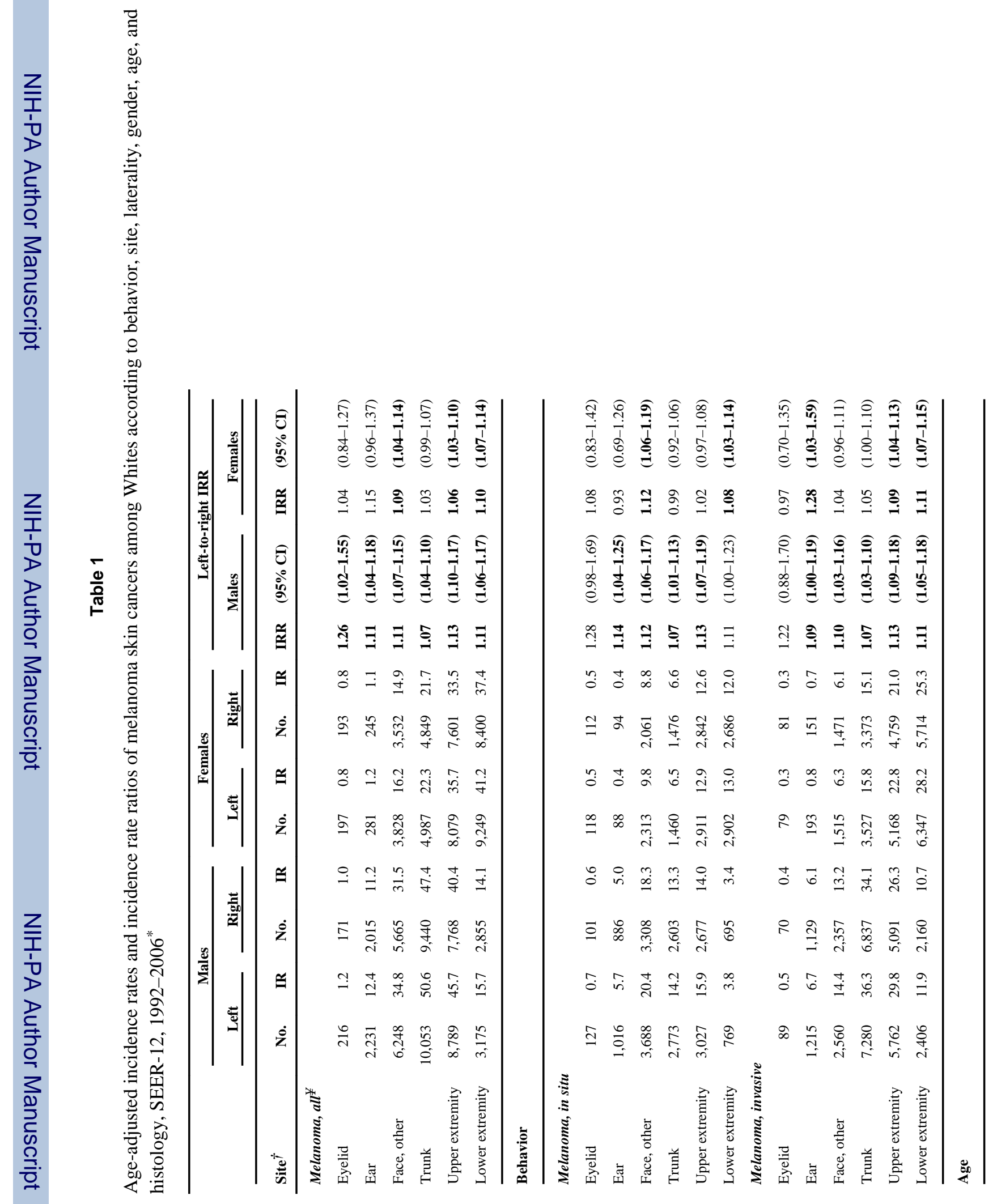


Dores et al.

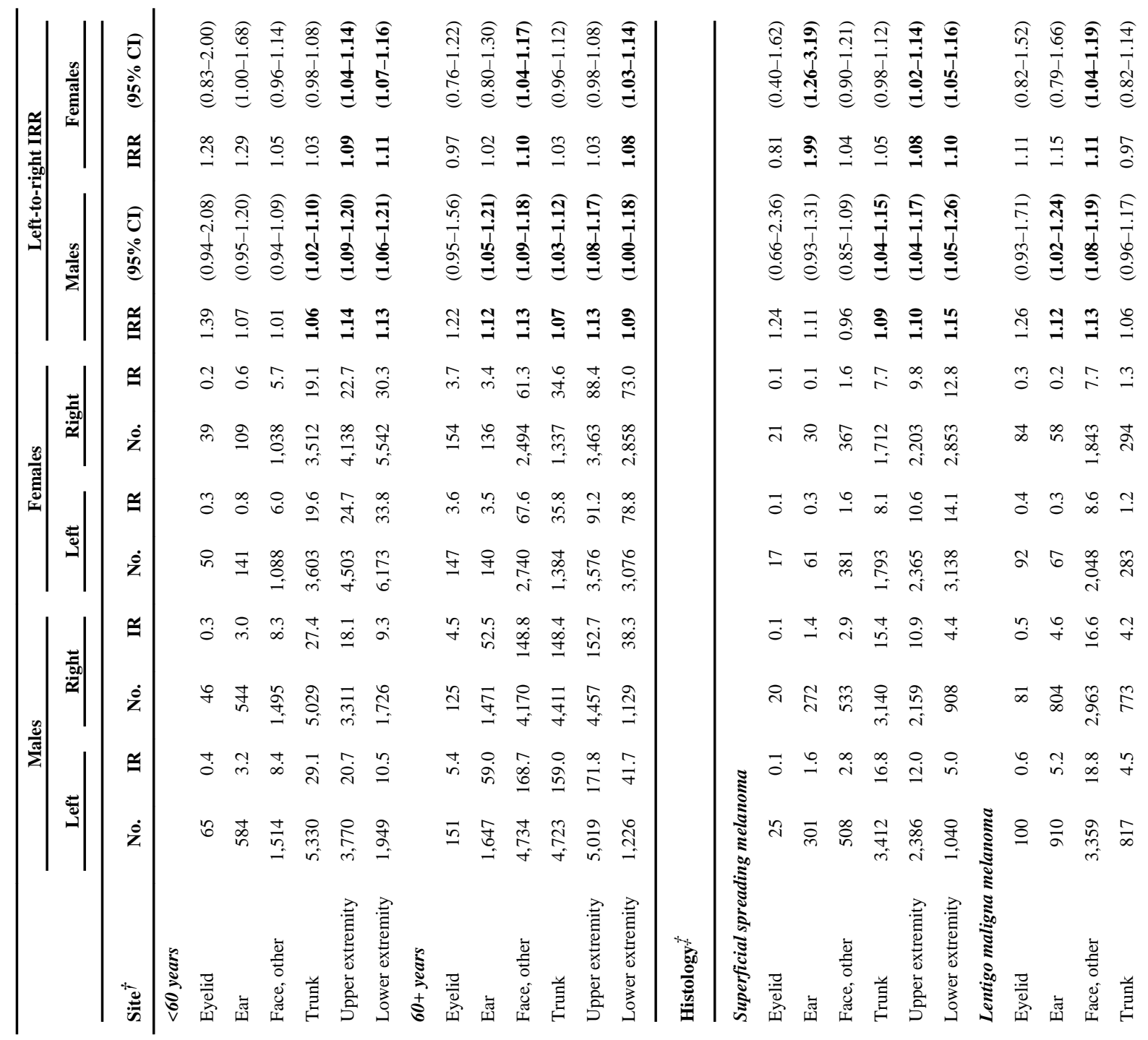


